\title{
Gönen (Biga Yarımadası) Kuzeybatısında Yer Alan Granitin Yaşına İlişkin İlk Bulgular, KB Anadolu
}

\author{
Firat Şengün* \\ Çanakkale Onsekiz Üniversitesi, Mühendislik Fakültesi, Jeoloji Mühendisliği Bölümü \\ 17.06.2019 Geliş/Received, 10.10.2019 Kabul/Accepted
}

\section{$\ddot{O} z$}

Biga Yarımadası'nda (KB Anadolu) Gönen'in kuzeybatısında yüzlek veren granitik kütlenin içerisindeki zirkon tanelerinden LA-ICPMS ile U-Pb izotop analizleri yapılmıştır. KD-GB yönelime sahip granit sarımsı kahve renkli olup feldspat ve kuvars mineralleri gözle ayırt edilebilmektedir. Granitik kütlenin üzerine uyumsuz bir dokanakla Jurasik yaşlı Bayırköy Formasyonuna ait kumtaşları ve gri, bej renkli Bilecik kireçtaşı gelmektedir. Granitlerin genel mineral bileşimi ortoklas, plajiyoklas, kuvars, biyotit, muskovit ve klorit minerallerinden oluşmaktadır. Aksesuar mineral olarak ise zirkon ve apatit mineralleri gözlenmektedir. Zirkon tanelerinin tamamı magmatik kökeni gösteren zonlanmaya sahiptir. Granit içerisindeki zirkon

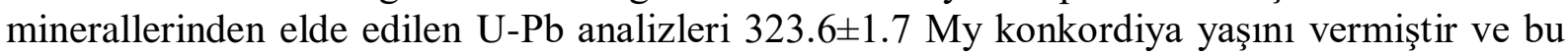
yaş granitlerin kristalizasyon yaşını ifade etmektedir. U-Pb yaşları Sakarya Zonu'nda Erken Karbonifer'de bir magmatizmanın olduğunu göstermektedir. Bu Erken Karbonifer magmatizması Variskan orojenezi sirasında tektonik birimlerin bir araya gelmesine neden olan yitim olayı ile ilgilidir. Sakarya Zonu'nun Variskan evrimi Karbonifer magmatizması, metamorfizması ve jeolojik evrimi bakımından Balkanlar'da, Pelagoniyan Zonu'nda, Rodop Masifi'nde ve orta Avrupa'da gelişen Karbonifer olaylarına benzerlik göstermektedir.

Anahtar Kelimeler: U-Pb, zirkon, granit, Karbonifer magmatizması, KB Anadolu,

\section{Preliminary Ages of Granitic Rocks in the Northwest of Gönen (Biga Peninsula), NW Anatolia}

\begin{abstract}
$\mathrm{U}-\mathrm{Pb}$ analyses of zircon grains from the granitic rocks exposed on the northwestern of Gönen in the Biga Peninsula (NW Anatolia) were performed by LA-ICPMS. NE-SW-trending granites have brownish yellow color and feldspar, quartz minerals are visible within granitic rocks. These granitic rocks are unconformably overlain by Jurassic sandstones of the Bayrrköy Formation and gray-colored Bilecik limestone. The main mineral assemblage of granites is composed of orthoclase, plagioclase, quartz, biotite, muscovite and chlorite. Zircon and apatite minerals occur as accessory minerals. Most zircon grains have oscillatory zoning

\footnotetext{
*Sorumlu Yazar (Corresponding Author): Frrat Şengün

(e-posta: firatsengun@comu.edu.tr)

Bu makale ÇOMÜ BAP Koordinasyon Birimince desteklenmiştir. Proje numarası: FBA-2018-2453

TÜBİTAK 2219 Yurt Dışı Doktora Sonrası Araştırma Burs Programı kapsamında desteklenmiştir.
} 
showing the magmatic origin. U-Pb analyses of zircon minerals from granitic rocks yielded the concordia age of $323.6 \pm 1.7 \mathrm{Ma}$ and this concordia age state the crystallization age of granites. U-Pb zircon age show that Early Carboniferous magmatism is present in the Sakarya Zone, which is related to subduction event resulted from the amalgamation of tectonic units during the Variscan orogeny. The Variscan evolution of the Sakarya Zone resembles the Carboniferous events in the Balkans, Pelagonian Zone, Rhodope Massif and central Europe in terms of Carboniferous magmatism, metamorphism and geological evolution.

Keywords: U-Pb, zircon, granite, Carboniferous magmatism, NW Anatolia,

\section{Giriş}

Granitler öncelikli olarak kıtasal kayaların kısmi ergimesiyle oluşur ve kıtasal bölgelerde yaygın olarak bulunmaktadır (Brown, 2013). Bu yüzden kıtasal kabukta en yaygın magmatik kaya tipi olan granitlerle ilgili çok sayıda çalışma yapılmıştır. Çeşitli tektonik ortamlarda oluşan granitler kıtasal kabuğun gelişmesi, yeniden oluşumu, kabuk-manto etkileşimi ve mineralizasyon hakkında önemli bilgiler sağlamaktadır. Bununla birlikte granitik kayalar farklı mineralojik topluluğa ve jeokimyasal bileşime sahip olması nedeniyle büyük farklılıklar göstermekle birlikte granitlerin sınıflaması, kökeni, tektonik ortamları granit petrojenezinde hala en çok tartışılan konulardır. Bundan dolayı granitlerin petrolojik özelliklerini ve kristalizasyon yaşlarının ortaya çıkarılması için granitlerin içerisinde aksesuar mineral olarak bulunan zirkonların U-Pb izotopik özelliklerinden yararlanılmaktadır. Zirkon $\left(\mathrm{ZrSiO}_{4}\right)$ birkaç farklı radyojenik (U-Th/Pb, U-Th/He) izotop analizlerini uygulayabilmek açısından nadir termodinamik ve kimyasal özellikler sunan bir mineraldir (Hanchar ve Hoskin, 2003).

$\mathrm{Bu}$ çalışmanın konusunu oluşturan granitik kütle KB Anadolu'da Sakarya Zonu'nun batı kesiminde yer alan Biga Yarımadası'nda yüzeylemektedir (Şekil 1.1). Sakarya Zonu Variskan metamorfizması-magmatizması, Permo-Triyasik Paleotetis yığışım-yitim karmaşıkları ve Liyas bölgesel uyumsuzluğun kırıntılı ürünleriyle karakterize olmaktadır. Variskan orojenezi sırasında kıtasal ve okyanusal bloklar Lavrasya'nın güney kenarında Sakarya Zonu'nun temeline yığılmışlardır (Okay ve ark., 2006; Okay ve Nikishin, 2015). Sakarya Zonu'nun batı kesiminde bulunan Biga Yarımadası Variskan ve Alpin olayları sırasında karmaşık termotektonik geçmişe sahiptir (Şekil 1.1) (Okay ve ark., 1996, 2006; Picket ve Robertson, 2004; Cavazza ve ark., 2009). Sakarya Zonu'nun temelinde yaygin olarak bulunan granitik kayaların büyük bir kısmı Karbonifer yaşlıdır (350-308 My) (Delaloye ve Bingöl, 2000; Okay ve ark., 2002, 2006; Topuz ve ark., 2007, 2010; Dokuz, 2011; Ustaömer ve ark., 2012; Kaygusuz ve ark., 2016; Şengün ve Koralay, 2017). Bu granitik kayalar Biga Yarımadası'nda Kazdağ Masifi'nden (329-308 My) (Okay ve ark., 1996, 2006; Erdoğan ve ark., 2013) doğuya doğru orta Sakarya Zonu'nda ( 290 My) (Okay ve ark., 2006; 327-319 My, Ustaömer ve ark., 2012) ve doğu Sakarya Zonu'nda (340-318 My) (Topuz ve ark., 2010; Dokuz, 2011; Kaygusuz ve ark., 2016) izlenebilmektedir. Sakarya Zonu'nun doğu kesiminde de Yusufeli'nden alınan granitlerde Karbonifer magmatizması saptanmıştır (356-325 My) (Ustaömer T ve ark., 2013).

Bu makalede Biga Yarımadası'nın doğu kesiminde Gönen kuzeybatısında yüzlek veren granitik kütlenin LA-ICPMS (lazer aşındırma-etkileşik çiftleşmiş plazmalı kütle spektrometresi) zirkon U-Pb yaşları ile kristalizasyon yaşının ortaya çıkarılması amaçlanmıştır. 


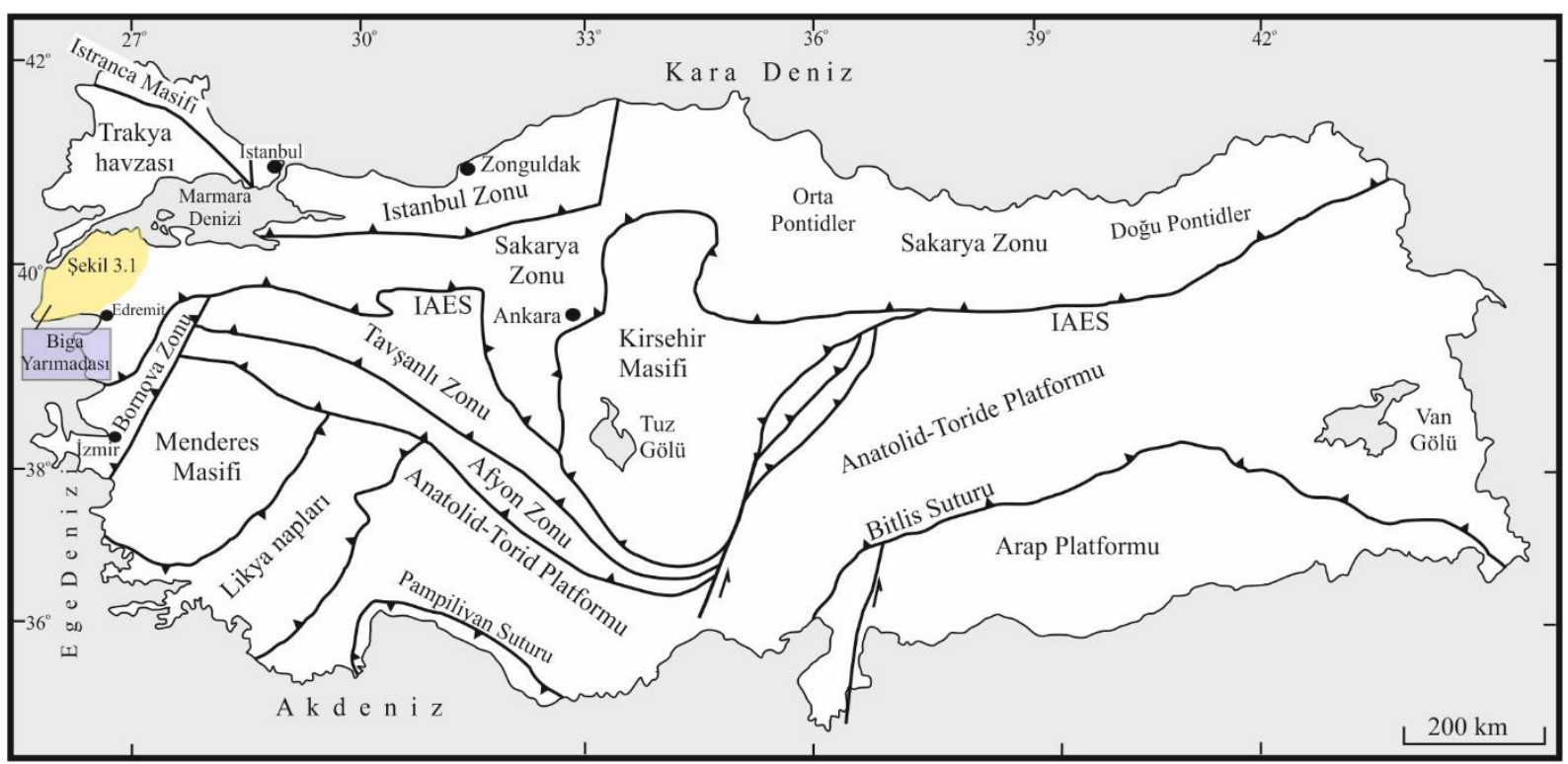

Şekil 1.1. Türkiye'nin ana tektonik birimlerini ve bunları sınırlayan süturları gösteren tektonik haritası (Okay ve Tüysüz, 1999'dan değiştirilmiştir).

\section{Materyal ve Yöntem}

\section{1. Örnek Hazırlama}

Çalışma alanı içerisindeki granit yüzleklerinden alınan 8-10 kg örnek içerisindeki zirkon taneleri klasik kırma, sallantılı masa, eleme, manyetik ayırıcı, ağır sıvı ile ayrılmış ve son olarak da binoküler mikroskop altında temiz, kapanım içermeyen zirkon taneleri seçilmiştir. $\mathrm{Bu}$ seçilmiş zirkon taneleri $\mathrm{U}-\mathrm{Pb}$ yaşlandırma analizleri için epoksi içerisine gömülmüş ve parlatılmıştır. Zirkon tanelerinin dış morfolojisini ve iç yapısını ortaya çıkarmak amacıyla katodolüminesans (CL) görüntüleri çekilmiştir. Zirkonların CL görüntüleri $\mathrm{U}-\mathrm{Pb}$ izotop analizlerinin yerlerinin seçilmesinde kullanılmıştır. CL analizleri Göteborg Üniversitesi'nde Hitachi S-3400N taramalı elektron mikroskobu (SEM) kullanarak zirkon içerisindeki kapanımları tanımlamak, U-Pb izotop analizleri için en uygun analiz yerlerini seçmek amacıyla yapılmıştır. Elektron mikroskobunda görüntüleme sırasında analiz koşulları $20 \mathrm{kV}$ ve $6.04 \mathrm{nA}$ olarak ayarlanmıştır. Örnekler SEM-CL analizleri öncesinde karbonla kaplanmıştır. Analizden sonra ise $1 \mu \mathrm{m}$ alüminyum oksit $\left(\mathrm{Al}_{2} \mathrm{O}_{3}\right)$ tozuyla karbonla kaplanmış örneğin karbonunun çıkarılması ve daha sonra örneğin ultrasonik temizleme banyosunda 5 dakika kalıp tamamen temizlenmesi sağlanmıştır.

\subsection{Zirkon U-Pb Analizleri}

$\mathrm{U}-\mathrm{Pb}$ yaşlandırma analizleri Oslo Üniversitesinin yer bilimleri bölümünde bulunan $\mathrm{Nu}$ Plazma HR çoklu toplayıcıya monte edilmiş NewWave LUV 213 ND-YAG ve Cetac LSX213 G2+ lazer mikroprobu kullanarak LA-ICPMS ile gerçekleştirilmiştir. Sistemde taşıyıcı gaz olarak He-Ar gazı kullanılmıştır. Helyum gazı örneklerin bulunduğu örnek tutucudan lazer ile aşındırılmış örnek partiküllerini taşır ve taşıyıcı gaz olarak Argon hassasiyeti artırmak için ilave gaz olarak Nitrojen ile karışarak ICP-MS'in 1sı kaynağına doğru akar. Helyum aynı zamanda aşınma yüzeyinde birikmeyi önleyerek hassasiyeti artırır ve partiküllerin boyu nedeniyle parçalanmayı azaltır (Eggins ve ark., 1998). Lazer aşındırma koşulları $\sim 0.06 \mathrm{~J} / \mathrm{cm}^{2}$ lazer enerjisinde $40 \mu \mathrm{m}$ çapında lazer ş̧ını ve $10 \mathrm{~Hz}$ tekrarlanma hızı olarak ayarlanmıştır. U-Pb analizlerinin her biri için 80 saniye aralıklarla sinyaller 
kaydedilmiştir. İlk 20 saniye lazerin 1sınması sırasında arka planın analiz edilmesi için kullanılmıştır. İzleyen 40 saniyelik bekleme süresi lazerin zirkonu aşındırması için kullanılırken son 10 saniye ise sistemde analizden kalan iyonların temizlenmesi için kullanılmıştır. Analiz serileri 15 bilinmeyen taneden oluşmaktadır. Her 15 analizden sonra yaşı ve U-Pb bileşimi bilinen 2-4 tane uyumlu zirkon analizleri yapılmıştır. Kalibrasyon için kullanılan zirkonlar uluslararası zirkon standartlarıdır. Bu standartlar $\mathrm{GJ}\left({ }^{207} \mathrm{~Pb} /{ }^{206} \mathrm{~Pb}\right.$ yaş $=$ $609 \pm 1 \mathrm{My}$ ) (Jackson ve ark., 2004), $91500\left({ }^{207} \mathrm{~Pb} /{ }^{206} \mathrm{~Pb}\right.$ yaş $\left.=1065 \pm 1 \mathrm{My}\right)$ Wiedenbeck ve ark., 1995) ve A382 (Lauri ve ark., 2011). A382 standardı ortalama 1877 \pm 2 My yaşa sahiptir. $\mathrm{Nu}$ Plazmadan elde edilen veri dosyaları düzeltme için Microsoft Excel sayfasına aktarılmıştır. Konkordiya diyagramları Isoplot 3.71 (Ludwig, 2008) sürümü kullanılarak çizilmiştir.

\section{Bulgular ve Tartışma}

\subsection{Jeolojik Yerleşim}

Sakarya Zonu'nun batı kesiminde yer alan Biga Yarımadası kuzeyde Istranca Masifi ve Trakya Havzası ile güneyde İzmir-Ankara Sütüru ile batıda ise Ege denizi ile sınırlanmaktadır (Şekil 1.1). Biga Yarımadası genel olarak yüksek dereceli metamorfik kayalardan, ofiyolitik, magmatik ve magmatiklere eşlik eden volkanik kayalardan oluşmaktadır (Şekil 3.1). Biga Yarımadası'nda yüzlek veren ana kaya toplulukları: (1) amfibolit-granulit fasiyesinde metamorfizma geçirmiş Kazdağ Masifi'nin temel kayaları (Karbonifer) (Okay ve Satır, 2000a, b; Yaltırak ve ark., 2004; Duru ve ark., 2007; Cavazza ve ark., 2009), yeşilşist fasiyesinde Çamlıca metamorfik birimi (Şengün ve Çalık, 2007; Şengün ve ark., 2011) ve Karabiga metamorfik birimi (Geç Kretase) (Beccaletto ve ark., 2007; Aygül ve ark., 2012); (2) Biga Yarımadası'nın doğu kesiminde yüzlek veren Triyas-Erken Jurasik yaşlı Karakaya Karmaşığı (Okay ve Göncüoğlu, 2004); (3) yitim-yığışımla ilişkili Çetmi melanjı (Erken Kretase) (Okay ve ark., 1990; Beccaletto ve ark., 2005); ve (4) Permo-Triyasik Karadă metamorfik birimi (Okay ve ark., 1990; Beccaletto ve Jenny, 2004). Tersiyer sedimanter birimleri bütün birimleri uyumsuz olarak üzerlemektedir (Şekil 3.1). 


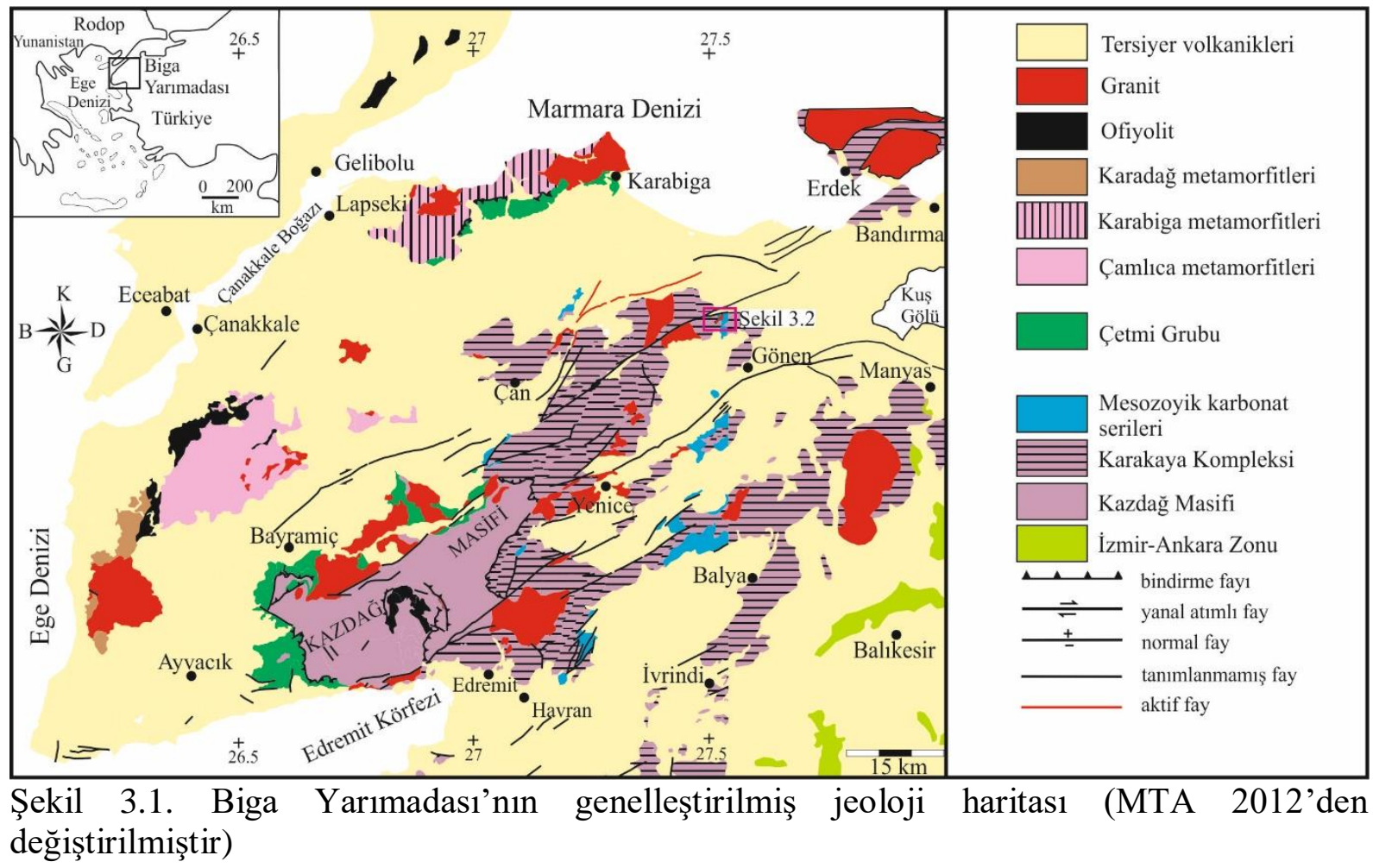

$\mathrm{Bu}$ makalenin konusunu oluşturan granitik kütle Gönen'in kuzeybatı kesiminde yüzlek vermektedir. En iyi yüzlekleri ise Hafız Hüseyinbey köyü civarında gözlenmektedir (Şekil 3.2). Granitik kütle KD-GB yönelimli olup yaklaşık $1 \mathrm{~km}^{2}$ lik alanı kaplamaktadır. Arazide genellikle altere olmuş olarak gözlenen granitler kahverengi sarımsı renktedir (Şekil 3.3a). Feldspat ve kuvars mineralleri gözle ayırt edilebilmektedir. Granitik kütlenin üzerine uyumsuz bir dokanakla Jurasik yaşlı Bayırköy Formasyonuna ait kumtaşları ve gri, bej renkli Bilecik kireçtaşı gelmektedir (Şekil 3.3b). Genel olarak sarı-kırmızı renkli konglomera, sarımsı kahve renkli kumtaşı, silttaşı ve killi kireçtaşlarından oluşan Bayırköy Formasyonu, Hafız Hüseyinbey köyü civarında Karakaya Karmaşığının düşük dereceli metamorfik kayaları (Nilüfer Birimi) üzerine açılı uyumsuzlukla başlayan transgresif bir istif özelliği göstermektedir. Baskın litolojiyi oluşturan kumtaşları arazide açık kahverenkli, ince-orta taneli ve iyi tabakalanmalı olarak gözlenmektedir. Birimin tabanında kırmızı-sarı renkli, ortakalın tabakalı, çapraz katmanlı konglomeraların iyi yuvarlaklaşmış çakılları; kireçtaşı, kuvarsit, granit, sleyt, kumtaşı ve bazaltlardan oluşmakla birlikte, daha üst seviyelerde breş şeklinde köşeli ve karbonat çimentolu cm-dm boyutlu, moloz akmalı çakılların çoğu kireçtaşlarından oluşan konglomeralardan oluşmaktadır. İstif en üstte yumrulu kireçtaşları ile başlayan Bilecik formasyonuna keskin bir dokanakla geçmektedir. Bilecik formasyonuna ait kireçtaşları sarımsı beyaz renkli, ince-orta kristalli, kalın tabakalı ve bol çatlaklı olarak gözlenmektedir. Bayırköy formasyonunun alt seviyelerinde bulunan kumtaşlarından alınan örneklerdeki fosil topluluğuna göre birimin yaşı Liyas olarak kabul edilmiştir (MTA, 2008). Jurasik yaşlı Bayırköy Formasyonunun üzerine gelen Bilecik kireçtaşı Geç Jura-Erken Kretase yaşlı kireçtaşlarından oluşmaktadır. 


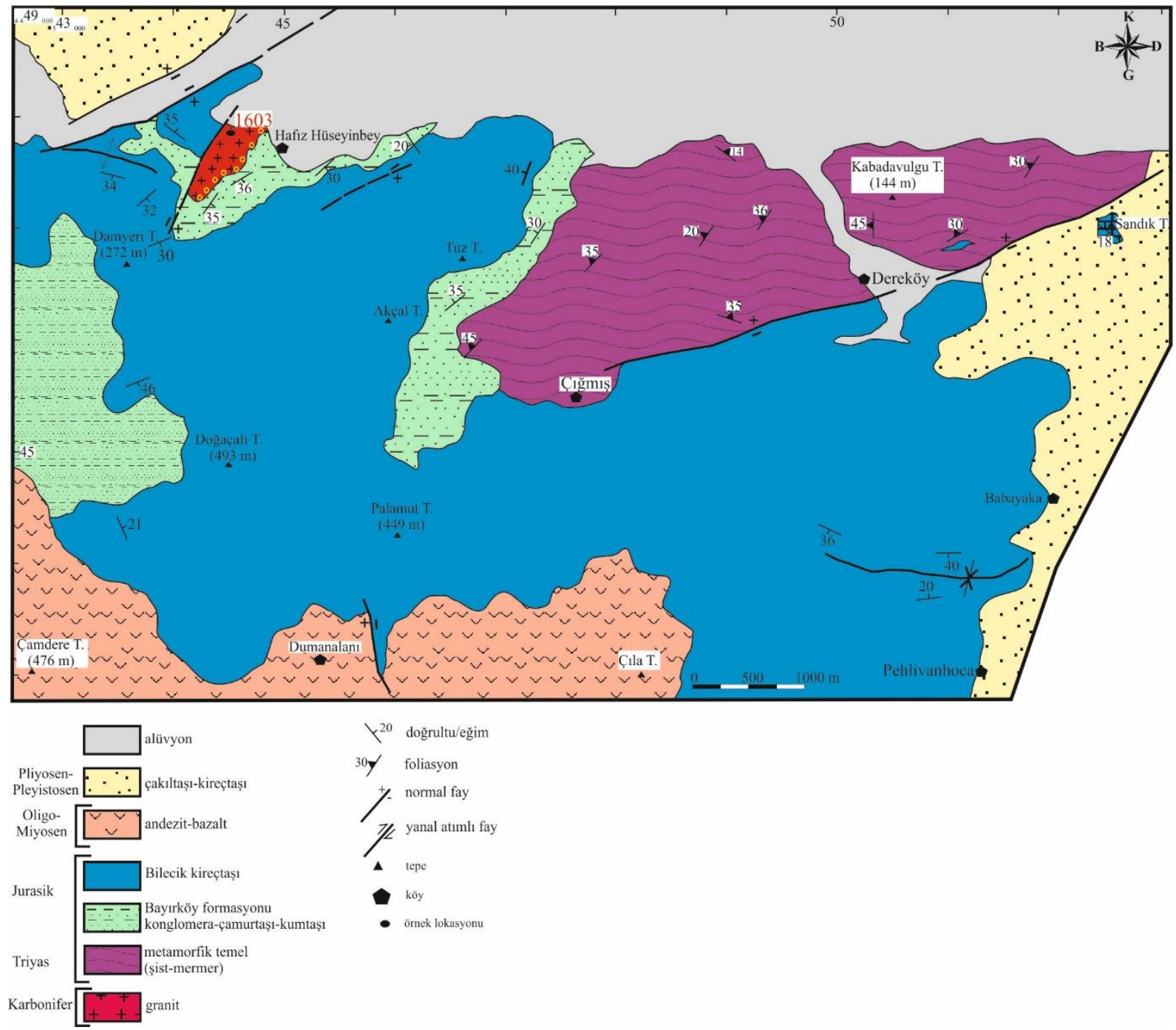

Şekil 3.2. Gönen (Balıkesir) kuzeyinin ayrıntılı jeoloji haritası ve U-Pb yaş analizi yapılan örneğin yeri (Yiğitbaş ve ark., 2009'dan değiştirilmiştir) 

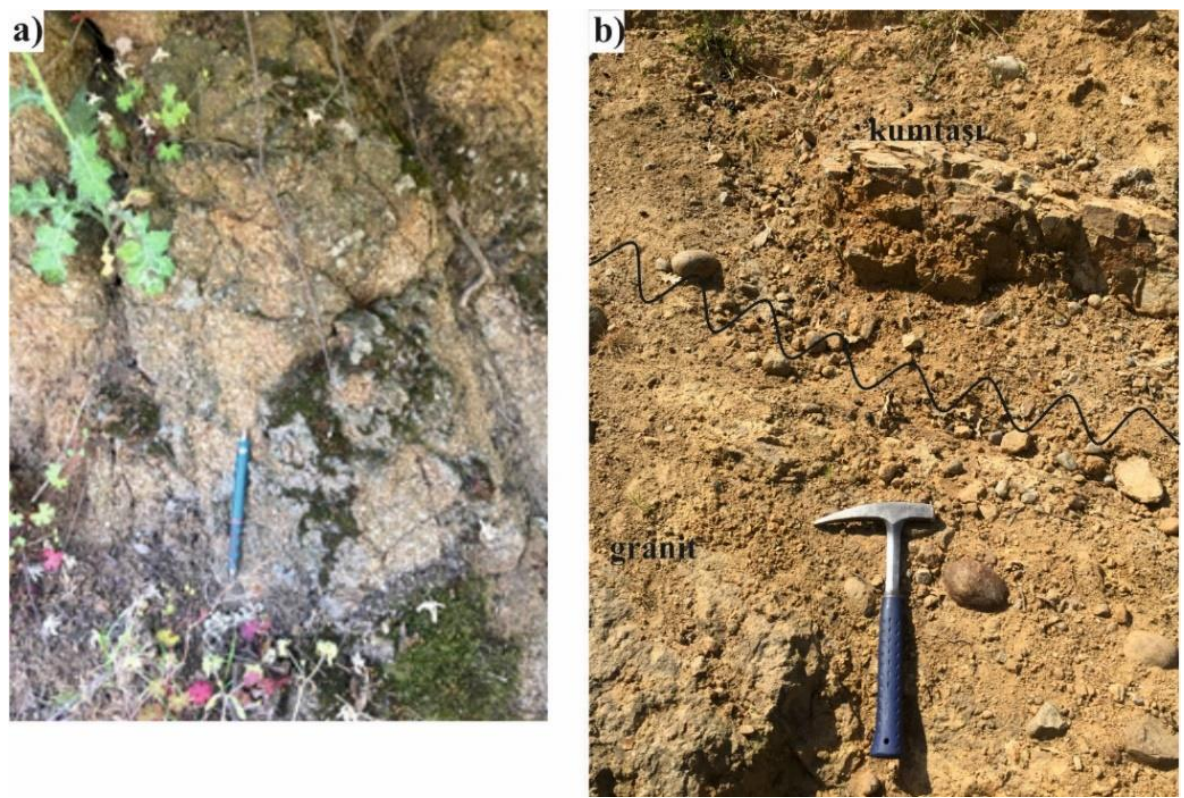

Şekil 3.3. (a) Alterasyona uğramış granitlerin genel görünümü (0544563K-4447589D). (b) Granitlerle Jurasik yaşlı Bayırköy Formasyonuna ait kumtaşları arasındaki uyumsuz dokanak ilişkisi (0544244K-4447488D).

\subsection{Petrografi}

Petrografik incelemeler sonucu granitin genel mineral bileşimi ortoklas, plajioklas, kuvars, biyotit, muskovit, klorit olarak saptanmıştır (Şekil 3.4a). Zirkon, apatit mineralleri ise aksesuar minerallerini oluşturmaktadır. Ortoklas kristalleri çift nikolde iri kristaller şeklinde, gri renkli ve karlspat ikizlenmesi göstermektedir (Şekil 3.4b). Bazı ortoklas kristalleri içerisinde plajiyoklas ve kuvars inklüzyonları gözlenmektedir (Şekil 3.4c). Ortoklas kristallerinin sınırlarında mirmekitik doku gelişmiştir (Şekil 3.4d). Plajioklas mineralleri çift nikolde beyazımsı gri renkte ve polisentetik ikizlenmesiyle kolaylıkla tanınabilmektedir. Kuvars mineralleri ise beyaz-gri renkli ve dalgalı sönme göstermektedir. Kuvars mineralleri arasındaki sınırlar genellikle düzdür. Biyotit mineralleri çift nikolde kırmızımsı, kahverengi girişim renklerine sahip tek nikolde ise kahverengi pleokroizma gösterirler. Biyotitlerin bir kısmı klorit minerallerine dönüşmüştür. Granit içerisinde makaslama hareketleri nedeniyle dalgalı sönme gösteren, uzamış beyazımsı gri renkli kuvars kristalleri gözlenmektedir. 

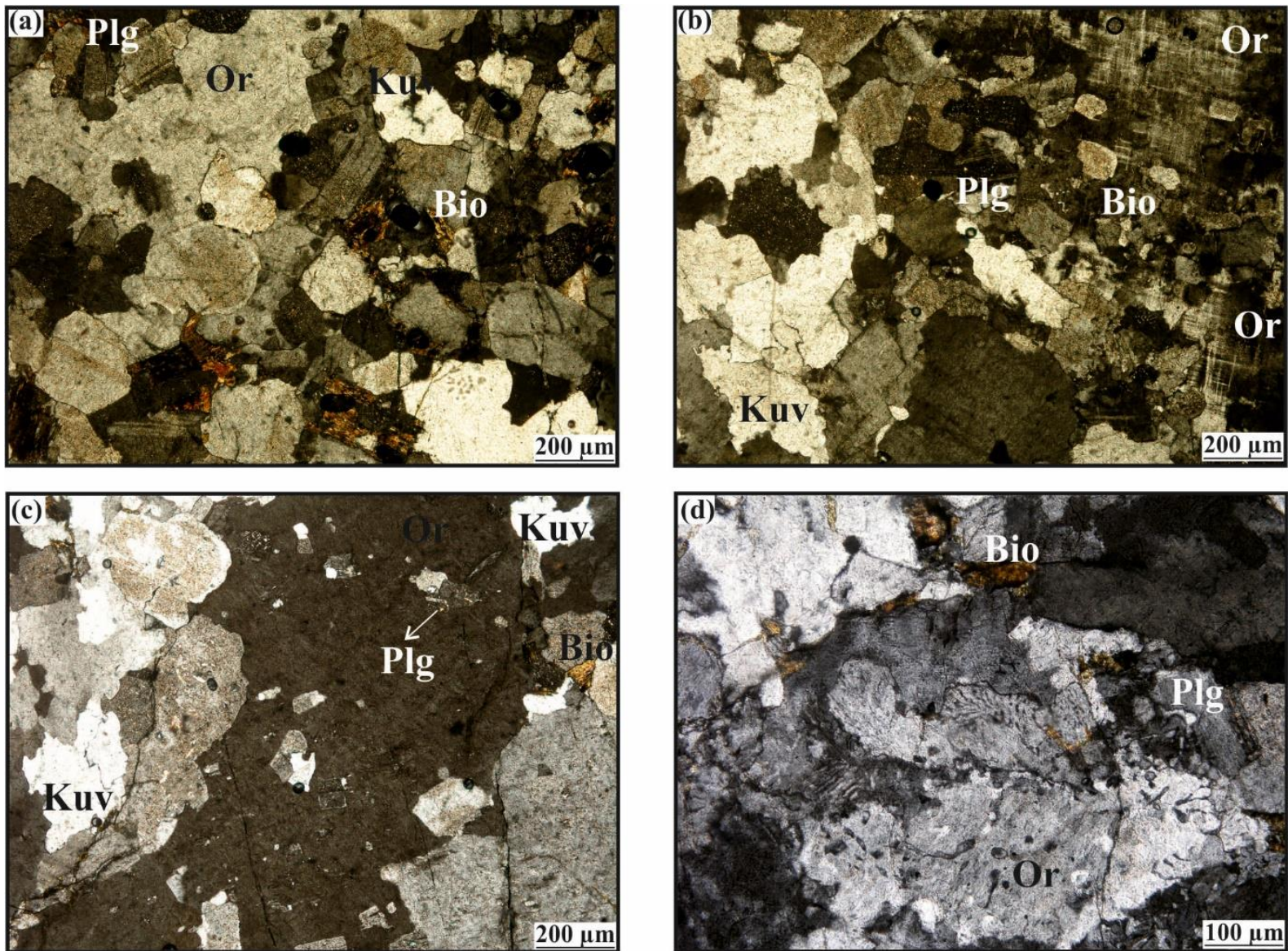

Şekil 3.4. (a) Granitlerin mikroskop altında genel görünümü. (b) Ortoklas minerallerinde gözlenen karlspat ikizlenmesi. (c) Ortoklas mineralleri içerisinde gözlenen kuvars ve plajioklas inklüzyonları. (d) Ortoklas minerallerinin kuvars ve plajiyoklas mineralleriyle olan sınırlarında gelişen solucan görünümlü mirmekitik doku (Or: ortoklas, Plg: plajiyoklas, Bio: biyotit, Kuv: kuvars)

\subsection{U-Pb Zirkon Yaşları}

$\mathrm{Bu}$ çalışmada U-Pb zirkon yaşlandırması için 1603 nolu granit örneğinden $(0544696 \mathrm{~K}-$ 4447370D) zirkon taneleri seçilmiştir. Seçilen zirkon taneleri renksiz, öz şekillidir ve boyutları 110 mikron ile 220 mikron arasında değişmektedir. Zirkon tanelerinin CL görüntüleri zirkonların zonlu bir içyapıya sahip olduğunu göstermektedir (Şekil 3.5). Bu zonlu iç yap1 granit örneği içerisindeki seçilmiş bütün zirkonların magmatik kökenli olduğunu göstermektedir. 


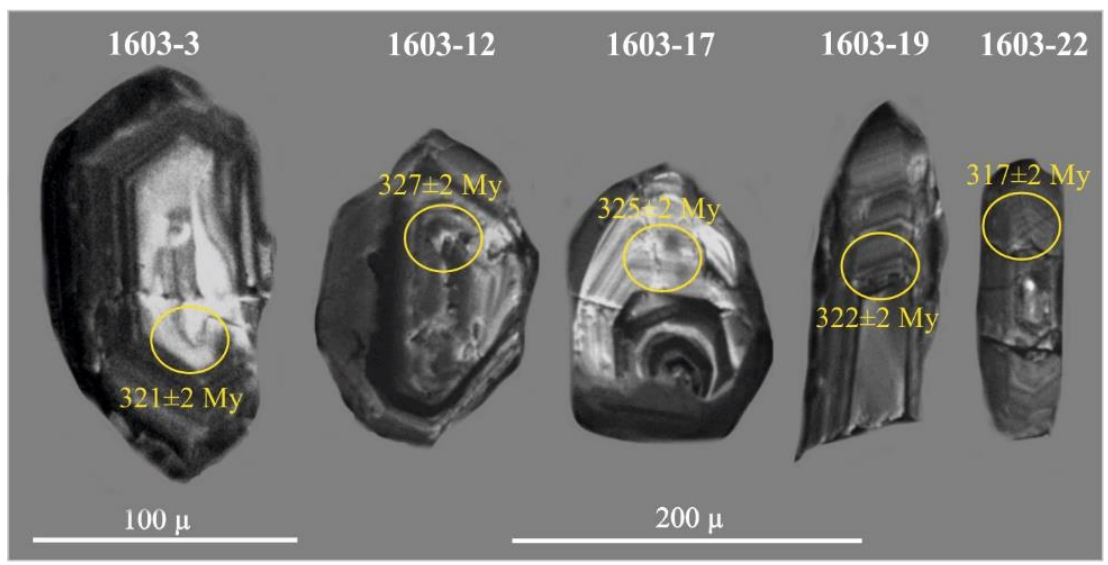

Şekil 3.5. 1603 nolu granit örneği içerisindeki seçilmiş zirkon tanelerinin katodolüminesans görüntüleri ( sarı halkalar U-Pb analizlerinin yapıldığı yerleri göstermektedir).

1603 nolu granit örneği içerisindeki zirkon tanelerinden U-Pb analizleri yapılmıştır. Zirkonların U-Pb izotop analizleri Çizelge 3.1 de verilmektedir. 5 zirkon tanesinden yapılan

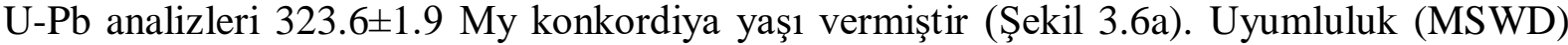
0.18 olarak hesaplanmıştır. Buna karşın Tera-Wasserburg diyagramında U-Pb yaşı ise 323.6 \pm 1.7 My (MSWD=0.044) yaş vermiştir (Şekil 3.6b). U-Pb izotop analizlerinin tamamı

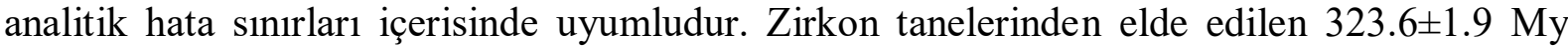
konkordiya yaşı granitin kristalizasyon yaşı olarak kabul edilmiştir.
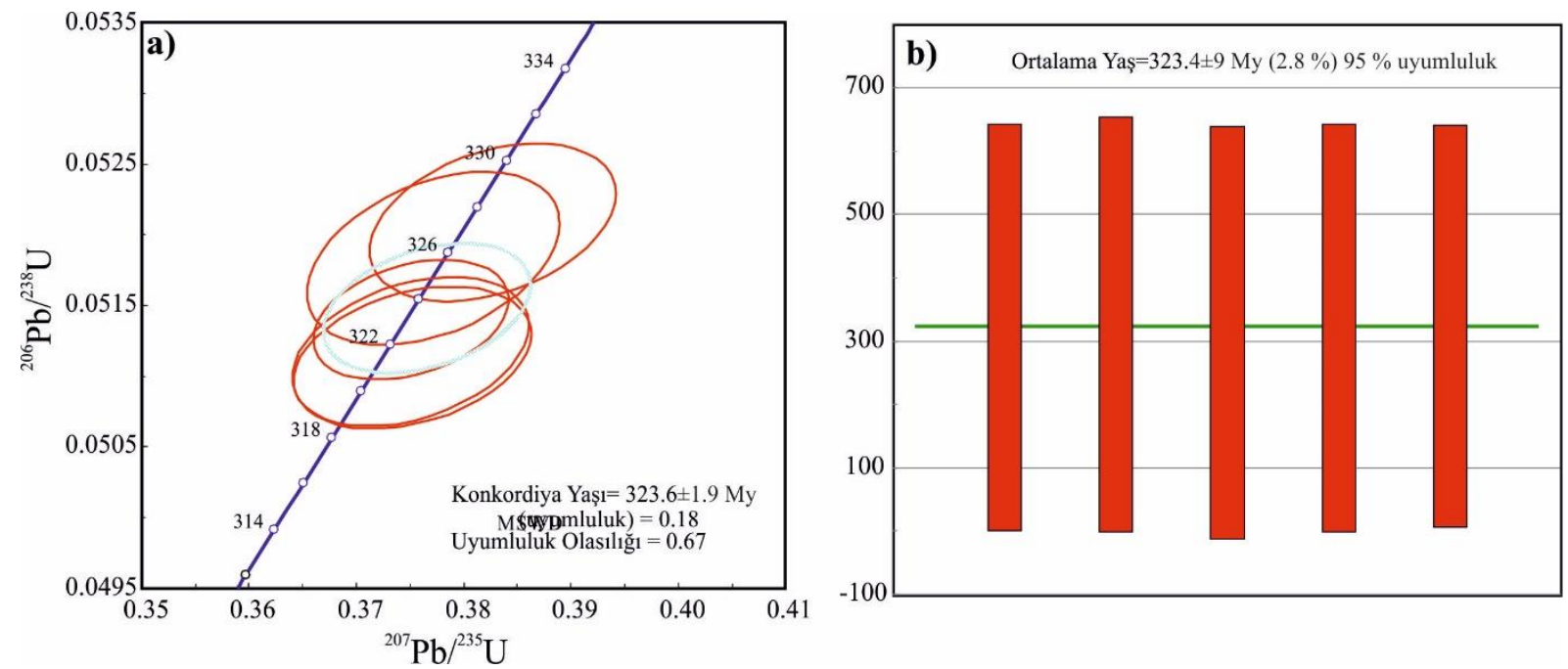

Şekil 3.6. LA-ICPMS ile U-Pb zirkon analizi yapılan 1603 nolu granit örneğine ait (a) konkordiya diyagramı, (b) Ortalama yaş diyagramı.

$\mathrm{Bu}$ çalışmadan elde edilen zirkon U-Pb yaşları Sakarya Zonu'nda Erken Karbonifer'de bir magmatizmanın olduğunu göstermektedir. Diğer yandan Orta Sakarya Zonu'nda Söğüt granodiyoritinden 327-319 My yaş elde edilmiştir (Ustaömer ve ark., 2012). Doğu Pontidler'de (Pulur Masifi, Kurtoğlu metamorfik kompleksi) ise magmatizmanın yaşı $324 \mathrm{My}$ ile 318 My arasında değişmektedir (Topuz ve ark., 2010; Dokuz, 2011). Doğu Pontidler'de erken Karbonifer magmatizması (356-325 My) aynı zamanda Yusufeli'nde yüzlek veren granitlerden de elde edilmiştir (Ustaömer ve ark., 2013). 
Çizelge 3.1. 1603 nolu granit örneği içerisindeki zirkonların LA-ICPMS U-Pb izotop analizleri

\begin{tabular}{|c|c|c|c|c|c|c|c|c|c|c|c|c|c|c|c|}
\hline \multirow[b]{2}{*}{ Örnek } & \multirow[b]{2}{*}{$\begin{array}{l}\text { Analiz } \\
\text { noktası }\end{array}$} & \multicolumn{6}{|c|}{ Oranlar } & & \multicolumn{6}{|c|}{ Yaş (My) } & \multirow{2}{*}{$\begin{array}{c}\begin{array}{c}\text { Uyumlulul } \\
(\%)\end{array} \\
\frac{{ }^{206} \mathrm{~Pb} /{ }^{238} \mathrm{U}}{{ }^{207} \mathrm{~Pb} /{ }^{235} \mathrm{U}}\end{array}$} \\
\hline & & ${ }^{207} \mathrm{~Pb} /{ }^{206} \mathrm{~Pb}$ & 1SE & ${ }^{207} \mathrm{~Pb} /{ }^{235} \mathrm{U}$ & 1SE & ${ }^{206} \mathrm{~Pb} /{ }^{238} \mathrm{U}$ & 1SE & Rho & ${ }^{207} \mathrm{~Pb} /{ }^{206} \mathrm{~Pb}$ & $1 \sigma$ & ${ }^{207} \mathrm{~Pb} /{ }^{235} \mathrm{U}$ & $1 \sigma$ & ${ }^{206} \mathrm{~Pb} /{ }^{238} \mathrm{U}$ & $1 \sigma$ & \\
\hline 1603 & $1603-03$ & 0.05322 & 0.00097 & 0.37520 & 0.00728 & 0.051131 & 0.00033 & 0.333 & 338 & 41 & 324 & 5 & 321 & 2 & 99.1 \\
\hline 1603 & $1603-12$ & 0.05328 & 0.00098 & 0.37713 & 0.00778 & 0.051833 & 0.000404 & 0.401 & 341 & 40 & 329 & 6 & 327 & 2 & 99.4 \\
\hline 1603 & $1603-17$ & 0.05198 & 0.00095 & 0.37505 & 0.00729 & 0.051178 & 0.000349 & 0.351 & 320 & 43 & 315 & 5 & 325 & 2 & 103 \\
\hline 1603 & 1603-19 & 0.05315 & 0.00097 & 0.38268 & 0.00754 & 0.052089 & 0.000371 & 0.362 & 335 & 40 & 323 & 5 & 322 & 2 & 99.7 \\
\hline 1603 & $1603-22$ & 0.05301 & 0.00106 & 0.37509 & 0.00602 & 0.051404 & 0.00028 & 0.333 & 353 & 42 & 325 & 6 & 317 & 2 & 97.5 \\
\hline
\end{tabular}


Sakarya Zonu'nun batı kesiminde Biga Yarımadası'nda metavolkanik kayalarda Erken Karbonifer magmatizması (334 My) saptanmıştır (Şengün ve Koralay, 2017). Sakarya Zonu'nda yaygın olarak gelişen Karbonifer magmatizması Variskan orojenezi surasında tektonik birimlerin bir araya gelmesine neden olan yitim olayına karşılık gelmektedir. Sakarya Zonu'nun Variskan evrimi Karbonifer magmatizmas1, metamorfizması ve jeolojik evrimi bakımından Balkanlar'da, Pelagoniyan Zonu'nda, Rodop Masifi'nde ve orta Avrupa'da gelişen Karbonifer olaylarına benzerlik göstermektedir. Bulgaristan ve Türkiye'nin kuzeyindeki Variskan magmatizması erken Karbonifer-erken Permiyen yaşındadır (320-270 My) (Okay ve ark., 2001, 2002; Carrigan ve ark., 2005; Sunal ve ark., 2006, 2008; Topuz ve ark., 2007, 2010; Ustaömer ve ark., 2012). Bununla birlikte bu çalışmadan elde edilen $323 \mathrm{My}$ yaş Bulgaristan, kuzey Türkiye ve Pelagoniyan Zonu'nda gelişen magmatizmadan biraz daha yaşlıdır.

Pelagoniyan Zonu boyunca Karbonifer magmatizması yaygın olarak gelişmiştir (Anders ve ark., 2007; Carrigan ve ark., 2005). Pelagoniyan Zonu'ndaki yitim zonu magmatizmasi ile ilgili Karbonifer temel kayalarının magmatizma yaşı 320 My dan 307 My değişmektedir (De Bono, 1998; Vavassis ve ark., 2000). Pelagoniyan Zonu ve Sakarya Zonu gibi diğer kıtasal parçalar erken Paleozoyik zamanında Gondvana' dan ayrılmışlar ve kuzeye Lavrasya aktif kıta kenarına doğru sürüklenerek yığılmışlardır (Stampfli ve ark., 2001; Stampfli ve Kozur, 2006; Robertson, 2012). Bu yüzden Lavrasya'nın güney kenarındaki magmatik yayın kalıntıları olan Karbonifer magmatik kayaları Paleotetis okyanusunun kuzeye doğru dalmasindan kaynaklanmaktadır (Şengün ve Koralay, 2017).

\section{Sonuç}

KB Anadolu'da Sakarya Zonu'nun batı kesiminde yer alan Biga Yarımadası'nda Gönen'in kuzeybatısında granitik bir kütle yüzlek vermektedir. Bu granitik kayalardan daha önce herhangi bir yaş elde edilmemiştir. Bu amaçla granitik kayalardan yaş tayini için zirkon taneleri ayırt edilmiştir. Zirkon tanelerinin tamamı magmatik kökeni gösteren zonlanmaya sahiptir. İlk kez bu çalışma kapsamında LA-ICPMS ile U-Pb zirkon yaşları elde edilmiştir.

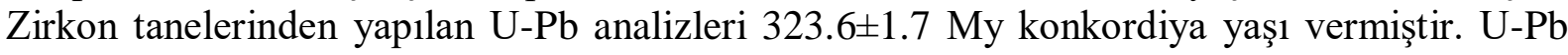
izotop analizlerinin tamamı analitik hata sınırları içerisinde uyumludur. Zirkon tanelerinde elde edilen 323.6 \pm 1.7 My yaşı granitlerin kristalizasyon yaşını ifade etmektedir. Bu çalışmadan elde edilen zirkon U-Pb yaşları Sakarya Zonu'nda Erken Karbonifer'de bir magmatizmanın olduğunu göstermektedir. Karbonifer magmatizması Sakarya Zonu'nda yaygın olarak gelişmiş ve Variskan orojenezi sırasında tektonik birimlerin bir araya gelmesine neden olan yitim olayına karşılık gelmektedir. Sakarya Zonu'nun Variskan evrimi Karbonifer magmatizması, metamorfizması ve jeolojik evrimi bakımından Balkanlar'da, Pelagoniyan Zonu'nda, Rodop Masifi'nde ve orta Avrupa'da gelişen Karbonifer olaylarına benzerlik göstermektedir. 


\section{Teșekkür}

Bu çalışma Çanakkale Onsekiz Mart Üniversitesi Bilimsel Araştırma Koordinasyon Birimi tarafindan FBA-2018-2453 no'lu projeyle ve TÜBİTAK 2219 Yurt Diş1 Doktora Sonras1 Araştırma Burs Programı kapsamında desteklenmiştir. Bu çalışma özgün araştırma makalesi niteliğindedir. 


\section{Kaynakça}

Anders B., Reischmann T., Kostopoulos D., 2007. Zircon geochronology of basement rocks from the Pelagonian Zone, Greece: constraints on the pre-Alpine evolution of the westernmost internal Hellenides. International Journal of Earth Sciences, 96:639-61.

Aysal N., Öngen S., Peytcheva I., Keskin M., 2012. Origin and evolution of the Havran Unit, Western Sakarya basement (NW Turkey): new LA-ICP-MS U-Pb dating of the metasedimentary-metagranitic rocks and possible affiliation to Avalonian microcontinent. Geodinamica Acta 25 (3-4): 226-247.

Beccaletto L., Jenny C., 2004. Geology and Correlation of the Ezine Zone: A Rhodope Fragment in NW Turkey? Turkish Journal of Earth Sciences, 13:145-176.

Beccaletto L., Bartolini A.C., Martini R., Hochuli P.A., Kozur H., 2005. Biostratigraphic data from Çetmi Melange, northwest Turkey: Palaeogeographic and tectonic implications. Palaeogeography Palaecology, 221:215-244.

Beccaletto L., Bonev N., Bosch D., Bruguier O., 2007. Record of a Palaeogene syn-collisional extension in the north Aegean Sea: evidence from the Kemer micaschists (NW Turkey). Geological Magazine, 144:393-400.

Bouvier A., Vervoort J.D., Patchett P.J., 2008. The Lu-Hf and Sm-Nd isotopic composition of CHUR: Constraints from unequilibrated chondrites and implications for the bulk composition of terrestrial planets. Earth and Planetary Science Letters, 273, 48-57.

Brown M., 2013. Granite: from genesis to emplacement. Geological Society of America Bulletin, 125, 1079-1113.

Carrigan C.W., Mukasa S.B., Haydoutov I., Kolcheva K., 2005. Age of Variscan magmatism from the Balkan sector of the orogen, central Bulgaria. Lithos, 82:125-147.

Cavazza W., Okay A.I., Zattin M., 2009. Rapid early-middle Exhumation of the Kazdağ Massif (western Anatolia), International Journal of Earth Sciences, 98: 1935-1947.

De Bono A., 1998. Pelagonian Margins in central Evia island (Greece): Stratigraphy and geodynamic evolution. Dissertation, Universite de Lausanne. (Doktora Tezi). 
Delaloye M., Bingöl E., 2000. Granitoids from Western and Northwestern Anatolia: Geochemistry and Modeling of Geodynamic Evolution. International Geology Review, 42:241-268.

Dokuz A., 2011. A slab detachment and delamination model for the generation of Carboniferous high-potassium I-type magmatism in the Eastern Pontides, NE Turkey: The Kose composite pluton. Gondwana Research, 19:926-944.

Duru M., Pehlivan Ş., Ilgar A., Dönmez M., Akçay A.E., 2007. 1/100000 ölçekli Türkiye Jeoloji Haritaları Serisi: Ayvalık İ17 paftası, MTA.

Eggins S., Kinsley L., Shelley J., 1998. Deposition and element fractionation processes during atmospheric pressure laser sampling for analysis by ICP-MS. Applied Surface Science, 127-129, 278-286.

Erdoğan B., Akay E., Hasözbek A., Satır M., Siebel W., 2013. Stratigraphy and tectonic evolution of the Kazdağ Masif (NW Anatolia) based on field studies and radiometric ages. International Geology Review, 55, 2060-2082.

Hanchar J.M., Hoskin P.W.O., 2003. Zircon. Review Mineral and Geochemistry, 53, 500.

Jackson S.E., Pearson N.J., Griffin W.L., Belousova E.A., 2004. The application of laser ablation-inductively coupled plasma-mass spectrometry to in situ $\mathrm{U}-\mathrm{Pb}$ zircon geochronology. Chemical Geology, 211, 47-69.

Kaygusuz A., Arslan M., Sipahi, F., Temizel, İ., 2016. U-Pb zircon chronology and petrogenesis of Carboniferous plutons in thenorthern part of the Eastern Pontides, NE Turkey: Constraints forPaleozoic magmatism and geodynamic evolution. Gondwana Research, 39, 327-346.

Lauri L.S., Andersen T., Hölttä P., Huhma H., Graham S., 2011. Evolution of the Archaean Karelian province in the Fenno scandian Shield in the light of $\mathrm{U}-\mathrm{Pb}$ zircon ages and $\mathrm{Sm}-\mathrm{Nd}$ and $\mathrm{Lu}-\mathrm{Hf}$ isotope systematics. Journal of the Geological Society, London 168, 201-218.

Ludwig K.R., 2008. User's Manual for Isoplot 3.70. Berkeley Geochronology Center, Special Publication, 4. 
MTA, 2008. 1/500000 ölçekli Türkiye Jeoloji Haritaları, Adana Paftası. Maden Tetkik ve Arama Genel Müdürlüğü yayınları. Ankara, Türkiye.

MTA, 2012. General and economic geology of the Biga Peninsula. Special Publication Series 28, 326 p. (in Turkish).

Okay A.I., Satır M., 2000a. Upper Cretaceous Eclogite - Facies Metamorphic Rocks from the Biga Peninsula, Northwest Turkey. Turkish Journal of Earth Sciences, 9:47-56.

Okay A.I, Satır M., 2000b. Coeval plutonism and metamorphism in a latest Oligocene metamorphic core complex in Northwest Turkey. Geological Magazine, 137:495-516.

Okay A.I., Göncüoğlu M.C., 2004. The Karakaya Complex: A Review of data and concepts. Turkish Journal of Earth Sciences, 13:77-95.

Okay A.I., Nikishin A.M., 2015. Tectonic evolution of the southern margin of Laurasia in the Black Sea region. International Geology Review, 57(5-8):1051-1076.

Okay A.I, Siyako M., Bürkan K.A., 1990. Biga Yarımadası'nın Jeolojisi ve Tektonik Evrimi. Turkish Association Petroleum Geology Bulletin 2(1):83-121.

Okay A.I., Monod O., Monie P., 2002. Triassic blueschists and eclogites from northwest Turkey: Vestiges of the Paleo-Tethyan subduction. Lithos, 64:155-178.

Okay A.I, Satır M., Siebel W., 2006. Pre-Alpide and Mesozoic orogenic events in the Eastern Mediterranean region. Geological Society of London Memoirs, 32:389-405.

Okay A.I, Satır M., Maluski H., Siyako M., Monie P., Metzger R., Akyüz S., 1996. Paleo-and Neotethyan events in northwest Turkey. In: Yin A, Harrison M (eds) Tectonics of Asia, Cambridge University Press, Cambridge, 420-441.

Okay A.I, Satır M., Tüysüz O., Akyüz S., Chen F., 2001. The tectonics of the Strandja Massif: Variscan and mid- Mesozoic deformation and metamorphism in the northern Aegean. International Journal of Earth Sciences, 90:217-233.

Pickett E.A., Robertson A.H.F., 2004. Significance of the volcanogenic Nilüfer unit and related components of the Triassic Karakaya Complex for Tethyan subduction/accretion processes in NW Turkey. Turkish Journal of Earth Sciences, 13:97-143. 
Robertson A.H.F., 2012. Late Palaezoic-Cenozoic tectonic development of Greece and Albania in the context of alternative reconstructions of Tethys in the Eastern Mediterranean region. International Geology Review, 54 (4):373-454.

Stampfli G.M., Kozur H., 2006. Europe from the Variscan to the Alpine cycles. In: Gee DG, Stephenson R (eds) European lithosphere dynamics. Geological Society of London Memoirs, 32:57-82.

Stampfli G.M, Mosar J., Favre P., Pillevuit A., Vannay J.C., 2001. Permo-Mesozoic evolution of the western Tethyan realm: The Neotethys/East-Mediterranean connection, in: Ziegler PA, Cavazza W, Robertson AHFR, Crasquin-Soleau S (eds) Peri-Tethys Memoir 6: Peritethyan rift/wrench basins and passive margins, Mémoire Musée National Histoire Naturelle 186, 51-108.

Sunal G., Satır M., Natal'in B.A., Toraman E., 2006. Paleozoic Magmatic Events in the Strandja Masif. Geodinamica Acta, 19 (5):283-300.

Sunal G., Satır M., Natal'in B.A., Toraman E., 2008. Paleotectonic position of the Strandja massif and surrounding continental blocks based on zircon $\mathrm{Pb}-\mathrm{Pb}$ age studies. International Geology Review, 50:519-545.

Şengün F., Çalık A., 2007. Çamlıca Metamorfitlerinin (Biga Yarımadası, KB Türkiye) Metamorfizma Özellikleri ve Korelasyonu. Geological Bulletin of Turkey, 50:1-16.

Şengün F., Yigitbas E., Tunç İ.O., 2011. Geology and Tectonic Emplacement of Eclogite and Blueschist, Biga Peninsula, Northwest Turkey. Turkish Journal of Earth Sciences, 20:273-285.

Şengün F., Koralay O.E., 2017. Early Variscan magmatism along the southern margin of Laurasia: Geochemical and geochronological evidence from the Biga Peninsula, NW Turkey. International Journal of Earth Sciences, 106, 811-826.

Topuz G., Altherr R., Schwarz W.H., Dokuz A., Meyer H., 2007. Variscan Amphibolitefacies Rocks from the Kurtoğlu Metamorphic Complex (Gümüşhane Area, Eastern Pontides, Turkey). International Journal of Earth Sciences, 96:861-873.

Topuz G., Altherr R., Siebel W., Schwarz W.H., Zack T., Hasözbek A., Barth M., Satır M., Şen C., 2010. Carboniferous high-potassium I-type granitoid magmatism in the Eastern Pontides: the Gümüşhane pluton (NE Turkey). Lithos, 116:92-110. 
Ustaömer P.A., Ustaömer T., Robertson A.H.R., 2012. Ion Probe U-Pb dating of the Central Sakarya basement: a peri-Gondwana terrane intruded by late Lower Carboniferous subduction/collision-related granitic rocks. Turkish Journal of Earth Sciences, 21:905932.

Ustaömer T., Robertson A.H.R., Ustaömer P.A., Gerdes A., Peytcheva I., 2013. Constraints on Variscan and Cimmerian magmatism and metamorphism in the Pontides (YusufeliArtvin area), NE Turkey from U-Pb dating and granite geochemistry. In: Robertson AHF, Parlak O, Ünlügenç UC (eds) Geological development of Anatolia and the easternmost Mediterranean region. Geological Society of London, 372:49-74.

Ustaömer T., Ustaömer P.A., Robertson A.H.F., Gerdes A., 2016. Implications of U-Pb and $\mathrm{Lu}-\mathrm{Hf}$ isotopic analysis of detrital zircons for the depositional age, provenance and tectonic setting of the Permian-Triassic Palaeotethyan Karakaya Complex, NW Turkey, International Journal of Earth Sciences, 105, 7-38.

Vavassis I., De Bono A., Stampfli G., Giorgis D., Valloton A., Amelin Y., 2000. U-Pb and Ar-Ar geochronoligical data from the Pelagonian Basement in Evia (Greece). Geodynamic implications for the evolution of Paleotethys. Schweisz Mineralogy Petrology, 80:21-43.

Wiedenbeck M., Alle P., Corfu F., Griffin W.L., Meier M., Oberli F., von Quadt A., Roddick J.C., Spiegel W., 1995. 3 natural zircon standards for U-Th-Pb, Lu-Hf, trace-element and REE analyses. Geostandards Newsletter, 19, 1-23.

Yaltırak C., Okay A.I., 2004. Edremit körfezi kuzeyinde Paleotetis birimlerinin jeolojisi. Bulletin of Engineering of ITU 3 (1):67-79.

Yiğitbaş E., Şengün F., Tunç İ.O., 2009. Distribution and correlation of Mesozoic rock assemblages of NW Anatolia (TÜBİTAK Report, Project No; ÇAYDAG 108Y232), p. 118 (in Turkish). 